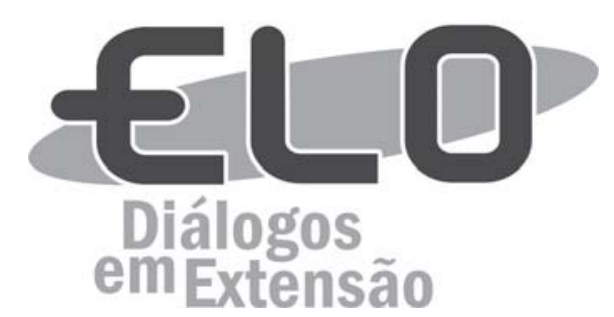

\title{
Disseminando conhecimentos sobre manejo da irrigação no cafeeiro
}

\author{
David Rafael Quintão Rosaํ, Natiélia Oliveira Nogueira², Cleiton Rodrigues Monteiro
}

\begin{abstract}
Resumo: Em razão dos baixos índices pluviométricos dos últimos anos, observa-se um aumento da área irrigada na cafeicultura. Esse aumento pode promover uma elevada pressão sobre os recursos hídricos de uma região. Nesse cenário, objetivou-se com este projeto difundir conhecimentos sobre o adequado manejo da irrigação principalmente para a cafeicultura familiar da região de Manhuaçu/MG. Para que os objetivos fossem alcançados a equipe de extensão elaborou uma ferramenta para ser utilizada no manejo da irrigação, além de materiais didáticos. Para a difusão do conhecimento foi realizada uma palestra. Também foram realizadas reuniões para debate de temas relacionados ao uso racional da água. Ao final, pode-se concluir que o projeto contribuiu para fomentar o debate democrático sobre o uso da água na cafeicultura, além de disponibilizar uma ferramenta simples e de fácil acesso para os cafeicultores irrigantes.
\end{abstract}

Palavras-chave: Recursos hídricos. Cafeicultura. Sustentabilidade.

Área Temática: Meio Ambiente. Tecnologia. Educação.

\section{Disseminating knowledge on irrigation management in coffee}

Abstract: Due to the lower rainfall frequencies of the last years, there is an increase of the irrigated area in coffee crop. This increase may create a high pressure on the water resources of a region. In this scenario, the aim of this project was to disseminate knowledge about the adequate management of irrigation, mainly for the family coffee industry in the Manhuaçu-MG. In order for the objectives to be achieved, the extension team developed a tool to be used in irrigation management, as well as didactic materials. For the diffusion of knowledge a lecture was given. Meetings were also held to discuss issues related to the rational use of water. In the end, it can be concluded that the project contributed to foment the democratic debate on the use of water in coffee cultivation, besides providing a simple and easily accessible tool for irrigating coffee growers.

Keywords: Water resources. Coffee-growing. Sustainability.

\section{Disseminando conocimientos sobre manejo de la irrigación en el cafeeiro}

Resumen: Debido a los bajos índices pluviométricos de los últimos años, se observa un aumento del área irrigada en la cafeicultura. Este aumento puede promover una elevada presión sobre los recursos hídricos de una región. En este escenario, se objetivó con este proyecto difundir conocimientos sobre el adecuado manejo del riego principalmente para la cafeicultura familiar de la región de Manhuaçu-MG. Para que los objetivos fueran alcanzados el equipo de extensión elaboró una herramienta para ser utilizada en el manejo del riego, además de materiales didácticos. Para la difusión del conocimiento se realizó una conferencia. También se realizaron reuniones para debate de temas relacionados al uso racional del

\footnotetext{
${ }^{1}$ Docente do Instituto Federal do Sudeste de Minas Gerais - Campus Manhuaçu. Rodovia BR 116 - Km 589,8 - Distrito Realeza - Manhuaçu/MG - telefone: (33) 33310101 e-mail: david. quintao@ifsudeste mg.edu.br

2 Docente do Instituto Federal do Sudeste de Minas Gerais - Campus Manhuaçu. Rodovia BR 116 - Km 589,8 - Distrito Realeza - Manhuaçu/MG - e-mail: natielia.nogueira@ifsudeste mg.edu.br

${ }^{3}$ Docente do Instituto Federal do Sudeste de Minas Gerais - Campus Manhuaçu. Rodovia BR 116 - Km 589,8 - Distrito Realeza - Manhuaçu/MG - e-mail: cleiton.monteiro@ifsudeste mg.edu.br
} 
agua. Al final, se puede concluir que el proyecto contribuyó a fomentar el debate democrático sobre el uso del agua en la cafeicultura, además de disponibilizar una herramienta simple y de fácil acceso para los caficultores irrigantes.

\section{Palabras clave: Recursos hídricos. Café. Sostenibilidad.}

\section{Introdução}

O café é um dos principais produtos agrícolas cultivados no Brasil, apresentando, atualmente, uma área total cultivada de aproximadamente 2.168,6 mil hectares (CONAB, 2018). Para o aumento da produtividade e qualidade do café, objetivos da cafeicultura, uma das técnicas utilizadas é a irrigação. Segundo levantamento realizado por Santinato, Fernandes e Fernandes (2008), cerca de $10 \%$ da área total cultivada no Brasil era irrigada, totalizando de 20 a $25 \%$ da produção nacional, naquele período.

A irrigação é definida com a técnica utilizada para o adequado fornecimento de água para as culturas, principalmente, em períodos de estiagem. No contexto climático atual evidencia-se a efetiva diminuição dos quantitativos pluviométricos em diversas regiões tradicionais na produção de café. Diante das situações observadas por Soares et al. (2005), no município de Viçosa-MG, e dos resultados apresentados por Lima, Custódio e Gomes (2008) para o município de Lavras-MG, pode-se inferir que este não é um cenário recente e que, a utilização da irrigação torna-se a única alternativa viável para a manutenção da produtividade e da qualidade dos grãos.

A crise hídrica tem sido uma das questões mais debatidas da atualidade, pois tem afetado o abastecimento de reservatórios para o consumo humano, para a indústria, para a geração de energia hidrelétrica e para as atividades agrícolas, sendo estas responsáveis por mais de $70 \%$ do consumo de água no País, a qual é utilizada para consumo animal e, principalmente, para a irrigação em culturas no intuito de garantir a produção sob condições de déficit hídrico. Importante ressaltar que, mediante a crise hídrica, pode ocorrer em algumas regiões casos de limitação do uso da água para irrigação, levando-se em consideração que a prioridade é o abastecimento da população humana.

Além da limitação do uso da água para a irrigação, diversos outros fatores têm ocasionado perdas nas atividades agrícolas, destacando-se, nos últimos anos, aqueles relacionados à prolongados períodos de déficit hídrico. Fernandes et al. (2016) afirmam, após analisarem seis safras consecutivas de café, que a irrigação da cultura é recomendável durante todo o ano, permitindo, assim, maiores médias de produtividade.

O experimento realizado em Lavras-MG, safra de 2001/2002, estudando três épocas de irrigação (01 de junho a 30 de setembro, 15 de julho a 30 de setembro e 01 a 30 de setembro) e os regimes hídricos, permitiu aos pesquisadores Silva, Faria e Reis (2003), observar que a irrigação realizada entre 01 de junho a 30 de setembro proporcionou a maior produção, 58 sacas ha-1 ${ }^{-1}$, correspondendo a uma produtividade $186 \%$ superior à não irrigada.

De acordo com Mantovani et al. (2006), a qualidade dos frutos do cafeeiro está relacionada à uniformidade de seu florescimento e, consequentemente, à uniformização da maturação; tais fatores estão aliados ao atendimento da demanda hídrica da cultura, principalmente, na fase de formação dos grãos.

Atualmente, os irrigantes dispõem de uma série de métodos para manejo da irrigação. Entretanto, em alguns casos, a falta de conhecimento técnico adequado e o custo financeiro para a implantação de um programa de manejo, tem resultado na obtenção de produtividades abaixo do previsto, além de promover o desperdício de água.

Diante do exposto, este projeto tem por objetivo fomentar o debate democrático com relação ao uso racional da água na cafeicultura irrigada. Especificamente, visa (i) disseminar conhecimentos sobre o manejo da irrigação e o uso racional da água na cafeicultura irrigada na região de Manhuaçu/ MG; e (ii) construir uma ferramenta para o manejo da irrigação, com o intuito de alterar a relação do irrigante com a utilização dos recursos hídricos locais.

O público-alvo deste projeto compreendeu os pequenos irrigantes da cafeicultura familiar localizados na região de Manhuaçu-MG, notadamente reconhecida como uma das principais regiões produtoras de cafés do estado de Minas Gerais, com uma produtividade de aproximadamente $24 \mathrm{sc} \mathrm{ha}^{-1}$ (CONAB, 2018). 
O município de Manhuaçu é o quarto maior produtor de café no Estado de Minas Gerais, sendo superado somente pelos municípios mineiros de Serra do Salitre, Três Pontas e Campos Gerais.

\section{Metodologia}

Para atendimento das demandas de conhecimento do público-alvo, e para oferecer uma ferramenta alternativa a ser utilizada no cotidiano do manejo da irrigação, o projeto foi subdividido em quatro fases metodológicas, entendendo que esta divisão proporcionaria um melhor gerenciamento das atividades.

A primeira fase buscou diagnosticar a demanda de informações pelo público-alvo. Para isso, foram levantadas as principais informações necessárias para incremento do conhecimento técnico dos pequenos irrigantes locais. Esse levantamento foi realizado mediante revisão de literatura e por meio de entrevistas com cafeicultores da agricultura familiar. Os entrevistados foram escolhidos de forma aleatória.

Em seguida, foi realizada uma pesquisa dos termos técnicos utilizados em manejo da irrigação. Tal pesquisa, possibilitou a elaboração de um glossário com a finalidade de "traduzir" essa linguagem técnica para uma linguagem mais acessível aos participantes.

De posse das informações coletadas, foram definidos os requisitos necessários para a construção da ferramenta de manejo da irrigação. Os requisitos deveriam apresentar características de simplicidade e fácil acesso.

Dando prosseguimento, a segunda fase teve como foco a elaboração de uma ferramenta para manejo da irrigação. Dessa forma, optou-se por uma ferramenta computacional baseada em cálculos matemáticos para manejo da irrigação na cultura do cafeeiro. O modelo conceitual e a arquitetura da ferramenta foram definidas com a finalidade de simplificar os processos utilizados no desenvolvimento, além de torná-la objetiva e eficaz. Concomitantemente, foi escolhida a sua interface visando à facilidade no processo de alimentação das informações necessárias aos cálculos, de forma que o usuário, intuitivamente, tivesse condições de operar o sistema.

Depois de finalizada a construção da ferramenta, foi testada mediante a inserção de coeficientes técnicos que retratassem as condições das lavouras cafeeiras da região onde se encontra o públicoalvo inserido.

Finalizada a construção da ferramenta, na terceira fase foram elaborados dois manuais: (i) um Manual Técnico contendo toda a base de cálculos da ferramenta, destinado à consultores técnicos e pessoas com conhecimentos específicos em irrigação; e (ii) um Manual do Usuário para suporte durante o manuseio da ferramenta. Durante as atividades do projeto, detectou-se a necessidade da elaboração de um manual de construção de um pluviômetro de baixo custo, para oferecer aos pequenos cafeicultores o conhecimento necessário para coleta de informações relativas à chuva de forma mais técnica possível.

Esses manuais foram elaborados visando aproximar os produtores de conceitos básicos relativos ao manejo da irrigação, e alertando para a necessidade de conhecer aspectos ligados ao clima e ao solo.

Por fim, a quarta fase buscou disseminar os conhecimentos sobre irrigação na cultura do cafeeiro e apresentar a ferramenta elaborada no projeto. Foram realizadas algumas reuniões e uma palestra de treinamento com o público participante.

As reuniões ocorreram nas dependências do Instituto Federal do Sudeste de Minas Gerais, Campus Manhuaçu. Estas atividades objetivaram, principalmente, a capacitação de alunos extensionistas para atuarem como disseminadores de boas práticas de manejo da irrigação na cultura do cafeeiro. Durante as reuniões foram realizadas mesas de discussão sobre o tema trabalhado e leitura de artigos técnicos.

A palestra de treinamento ocorreu em local externo ao Campus Manhuaçu e contou com a presença de cafeicultores de diversas cidades vizinhas ao município de Manhuaçu-MG. O objetivo dessa atividade era funcionar também como uma oficina de troca de saberes, ou seja, tanto a equipe extensionista do projeto quanto o público-alvo poderiam expor experiências exitosas referentes ao manejo da irrigação na cultura do cafeeiro. Acrescido a este fato, apresentou-se a ferramenta de manejo da irrigação e seus manuais, construídos durante a segunda e a terceira fases. 


\section{Resultados e Discussão}

Durante a fase de diagnóstico, foram realizadas reuniões para levantamento do nível de conhecimento do público-alvo e dos requisitos necessários para elaboração da ferramenta computacional.

Durante essa atividade também foram coletadas sugestões advindas de técnicos do setor (Figura 1). Neste momento, evidenciou-se que no cotidiano o irrigante necessita das respostas a três perguntas: Quando irrigar?; Qual a necessidade de água da cultura do café?; Por quanto tempo o sistema de irrigação deve ficar ligado?. Neste sentido, a elaboração da ferramenta e a transmissão de conhecimento basearam-se na resposta a estes questionamentos.

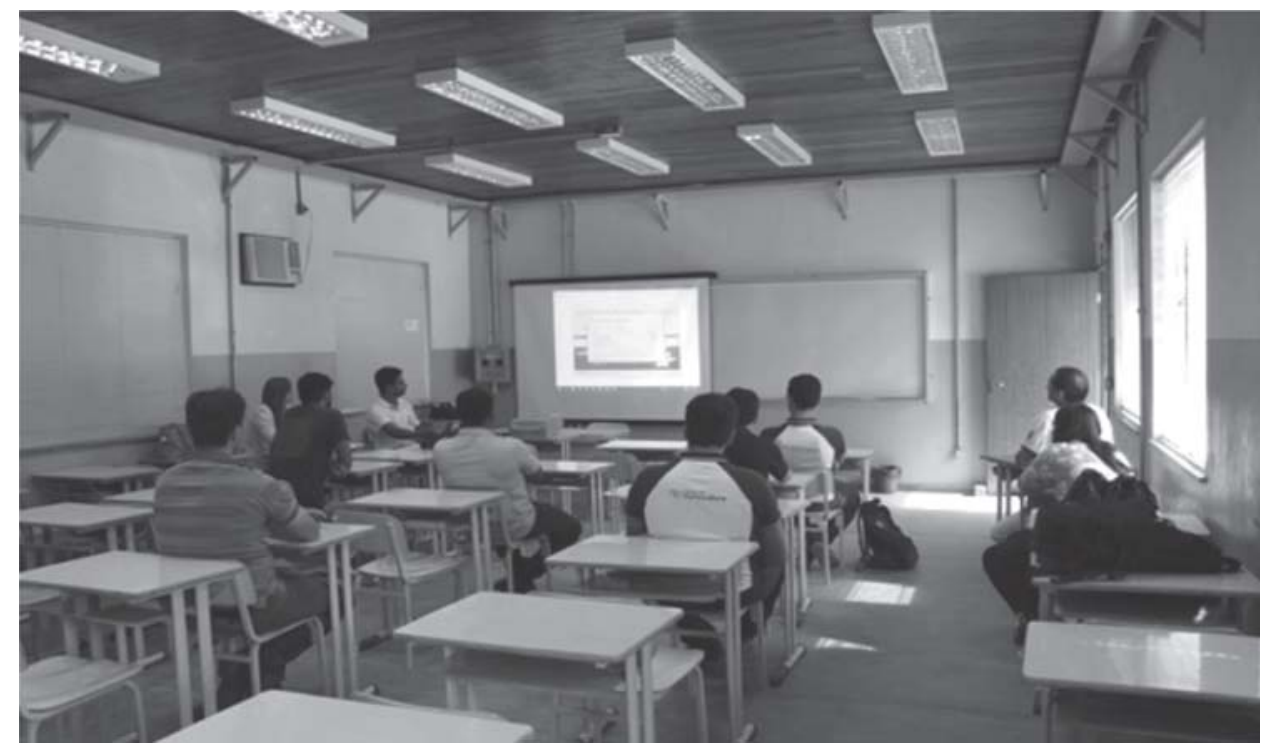

Figura 1 - Reunião para levantamento de conhecimento do público-alvo.

Fonte: Arquivo dos autores.

Outro fator observado é que a grande maioria dos irrigantes, localizados na região de atuação do projeto, não possui conhecimento mínimo de práticas de manejo da irrigação. Após este diagnóstico, os materiais didáticos, tais como o Manual do Usuário e o Manual Técnico, foram elaborados com conteúdo simples, apresentando definições básicas. Outra ação realizada foi a elaboração de uma palestra para apresentação e debate de conceitos básicos.

Durante essa fase, foi relatado pelos participantes das reuniões, diversas dificuldades relacionadas ao tipo e número de dados necessários para se obter resultados em outras tecnologias disponíveis, que objetivam servir de ferramenta para manejo da irrigação. Neste contexto, percebeu-se que as metodologias podem ser classificadas como complexas para o nível de conhecimento técnico dos pequenos produtores rurais. Além disso, um fator que pode ser visto como dificultador, está na necessidade de um número elevado de dados de entrada, pois, para a sua aquisição, seria necessário um elevado investimento financeiro, afastando, dessa forma, o público-alvo das soluções já disponíveis.

Para resolução das questões supracitadas, optou-se por elaborar uma ferramenta de manejo da irrigação (FIGURA 2a) fundamentada em estimativas de demanda de água do cafeeiro, utilizando modelos matemáticos mais simples e que necessitassem, em contrapartida, do menor número possível de variáveis de entrada para facilitar a configuração do sistema.

Segundo Mantovani et al. (2006) as necessidades hídricas podem ser determinadas por três vias: planta, solo e clima. Neste projeto, devido à facilidade de coleta e ao baixo investimento financeiro, optou-se por desenvolver a ferramenta baseada na estimativa das necessidades hídricas do cafeeiro pelo clima.

Com a finalidade de fornecer uma ferramenta de uso simples, eficaz e de baixo custo, foi elaborada uma Planilha Eletrônica para manejo da irrigação. Essa ferramenta pode ser utilizada para o cultivo do cafeeiro irrigado por gotejamento, ou seja, ela é específica para uma determinada cultura agrícola e para um sistema de irrigação, tornando a solução mais simples. 

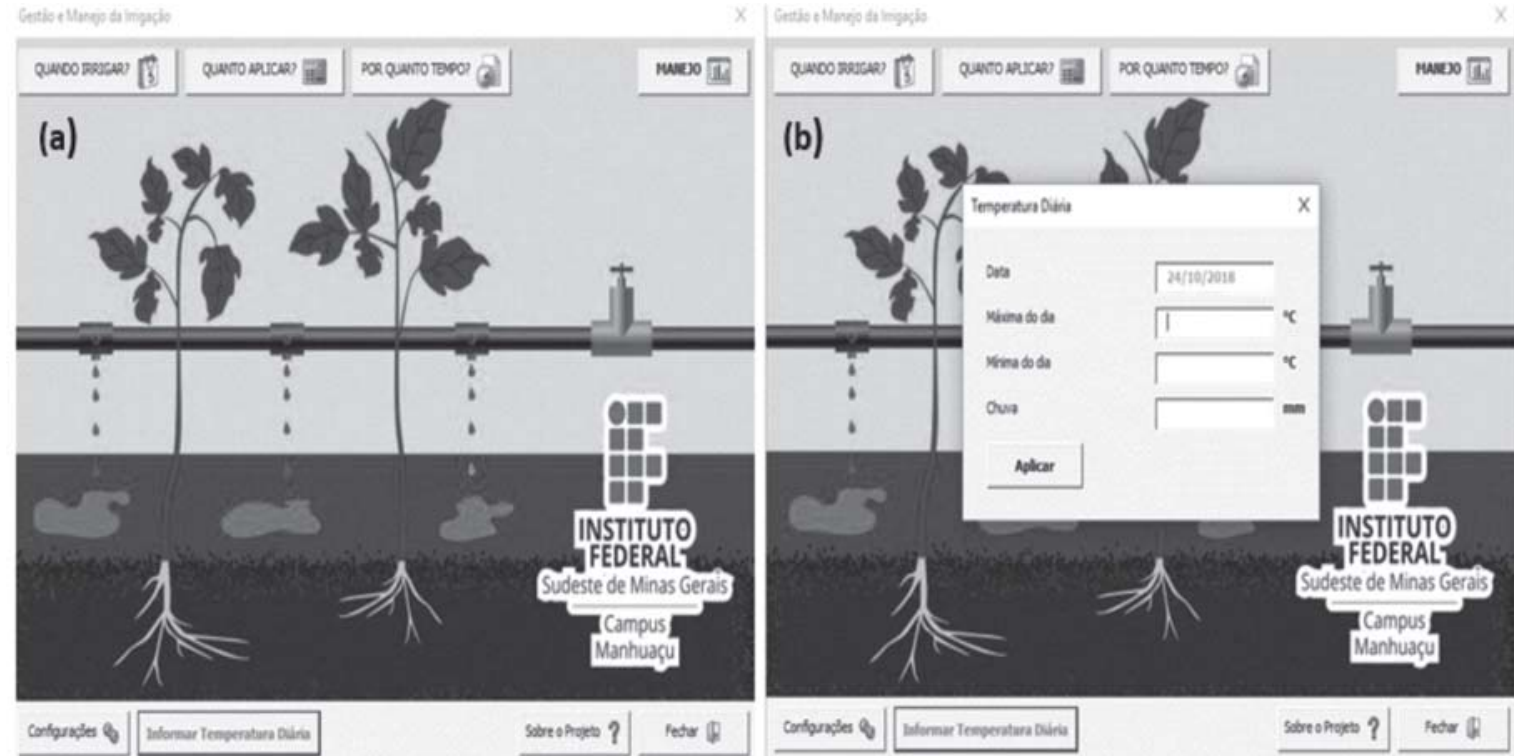

Figura 2 - Telas Iniciais da planilha eletrônica utilizada no manejo da irrigação, (a) tela inicial; (b) tela de inserção de valores de temperatura e chuva.

Fonte: Dados da pesquisa.

Para sua utilização da solução o usuário necessitará de dados da cultura, do solo, do clima e do sistema de irrigação. Após a inserção dos valores correspondentes a cada uma destas variáveis, o usuário deverá, diariamente, fornecer valores de temperatura máxima do ar $\left({ }^{\circ} \mathrm{C}\right)$, temperatura mínima do ar $\left({ }^{\circ} \mathrm{C}\right)$ e de chuva $(\mathrm{mm})$ (FIGURA $2 \mathrm{~b}$ ). Tais dados podem ser obtidos utilizando um simples Termômetro de Temperatura Máxima e Mínima, disponível no mercado no valor aproximado de $\mathrm{R} \$ 50,00$. Os dados relativos à chuva também devem ser fornecidos diariamente e, para a aquisição dos valores correspondentes a essa variável, o irrigante pode construir um Pluviômetro de baixo custo investindo, aproximadamente, $\mathrm{R} \$ 70,00$.

A planilha necessita ser configurada (FIGURA 3a) uma única vez, no início do manejo da irrigação. Essa etapa é necessária pois, para cada uma das variáveis de configuração, existem diferentes valores que são específicos de cada cultivo; logo após, a configuração da ferramenta se torna específica para cada situação.
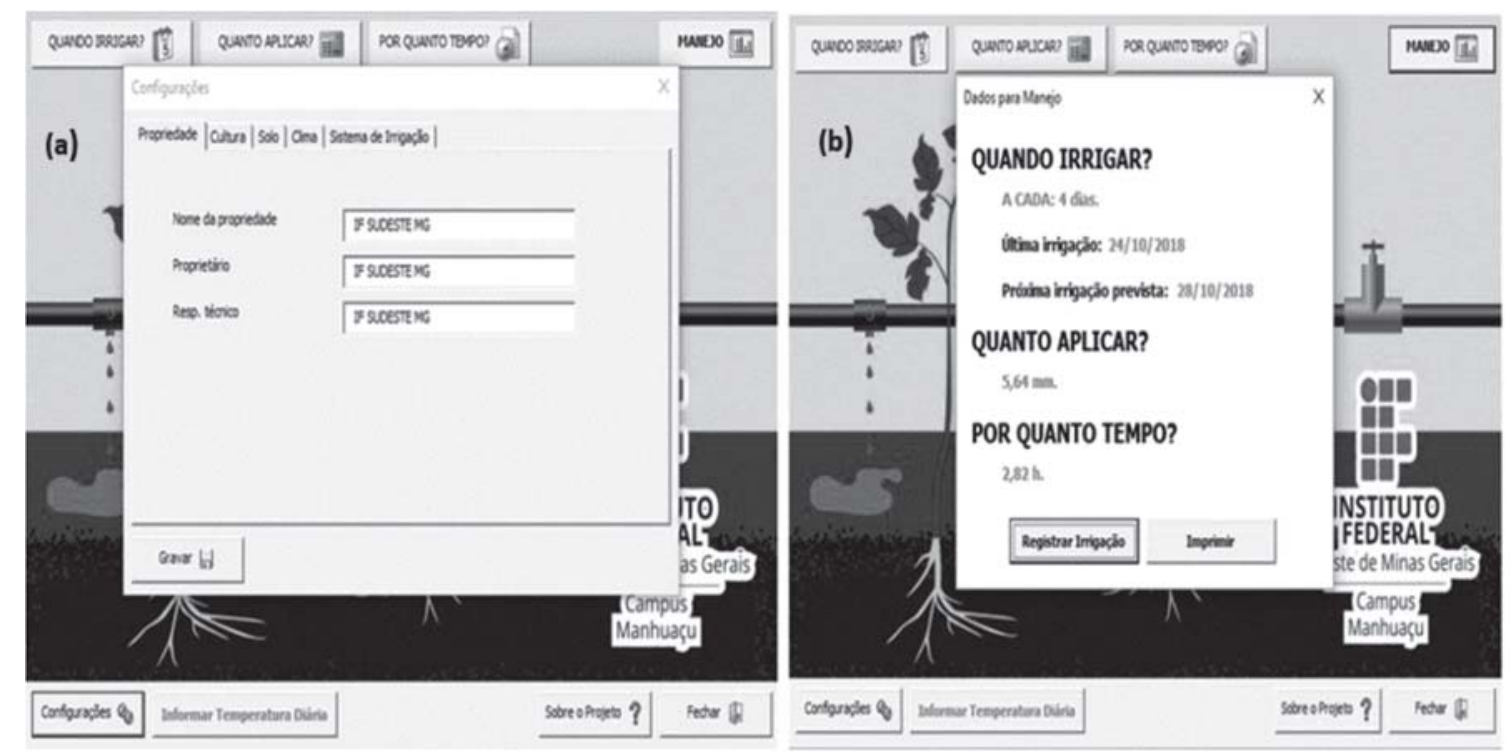

Figura 3 - Configuração do sistema e resultados apresentados, (a) Tela de Configuração do sistema; (b) relatório final de resultados.

Fonte: Dados da pesquisa. 
Após a configuração e inserção dos valores diários, é possível acessar as respostas às três perguntas supracitadas. Estas informações estarão disponíveis na parte superior da janela, e basta o usuário clicar em qualquer uma das perguntas para ter acesso a estas informações.

Um resumo contendo as respostas também foi criado para um melhor planejamento da irrigação; para tanto, o usuário tem à sua disposição o botão de Manejo. Com esta ferramenta é possível saber a quantidade de água a ser aplicada na cultura, o tempo de funcionamento do sistema de irrigação e obter o dia da próxima irrigação, tudo isso em um relatório de fácil compreensão. Porém, para a obtenção dos dias referentes à última irrigação e a próxima irrigação, o usuário deve registar o dia atual como um dia de irrigação; para tal, basta clicar no botão "Registrar irrigação" localizado no canto inferior esquerdo da janela. Na Figura 3b está apresentada a janela contendo as respostas de um exemplo de aplicação.

Finalizada a construção da ferramenta de manejo da irrigação, foram elaborados os Manuais. O Manual do usuário apresenta um passo a passo da metodologia de inserção de dados e cuidados a serem tomados durante a utilização da ferramenta. Este documento foi apresentado a membros do público alvo obtendo um resultado satisfatório, ou seja, os usuários que utilizarão a ferramenta com o apoio do manual conseguiram acessar todas as funcionalidades sem nenhuma restrição ao seu uso.

Na Figura 4 a, b, e c estão apresentadas as capas destes documentos. Ressalta-se que foram elaborados com linguagem mais simples possível, entretanto, o projeto possuía como objetivo a disseminação de conhecimentos referentes ao manejo da irrigação, assim os conceitos básicos foram mantidos e trabalhados durante palestras de divulgação da ferramenta. Estes manuais foram utilizados como materiais didáticos.

Em contrapartida, o Manual Técnico apresenta a base de cálculos incorporada na ferramenta desenvolvida para que todos os usuários, principalmente técnicos do setor cafeeiro, tenham acesso a metodologia utilizada. Esse manual serve também como documento técnico para a capacitação de pessoas e a disseminação da importância do correto manejo da irrigação e seu potencial para economia de água na cafeicultura irrigada.

Na última fase do projeto foram realizadas reuniões com o público alvo para a disseminação do conhecimento gerado durante a construção da ferramenta. Essa atividade pode ser classificada como a atividade principal deste projeto, haja vista que na fase de diagnóstico observou-se o baixo nível de conhecimento das pessoas envolvidas com o manejo da irrigação na região. Assim como a extensão busca a produção do conhecimento por meio da troca de saberes, entre o acadêmico e o popular, pautou-se neste momento por uma maior interação com os pequenos cafeicultores. Essa interação se deu a partir da realização de palestras e reuniões de apresentação da ferramenta. Durante as reuniões (FIGURA 5) foram simulados cenários de manejo da irrigação, aproveitando os questionamentos para dirimir as dúvidas apresentadas.

Durante as palestras foram apresentados conhecimentos básicos sobre a interação da água com solo, a importância da água para a fisiologia do cafeeiro, e a necessidade do uso racional da água de irrigação destacando cuidados com a manutenção da disponibilidade hídrica local, tendo como princípio o aumento da eficiência dos sistemas de irrigação. Segundo Vicente et al. (2015), a escassez de água em algumas regiões é um fator importante quando se analisa a eficiência com a qual as plantas utilizarão esse recurso, portanto, a escolha da quantidade de água a ser aplicada e a forma de manejo adotada deve levar em consideração estes aspectos.

Os conceitos relacionados às características físicas do solo foram aqueles nos quais se percebeu menor nível conhecimento. Assim, foram apresentados os conceitos básicos inerentes à interação da água no solo e a importância da retirada de amostras de solo para determinação de parâmetros físicos.

Outro tema apresentado nas palestras referiu-se à utilização da irrigação e ao incremento de produtividade do cafeeiro, advindo do emprego desta técnica. O aumento da produtividade do cafeeiro por meio da irrigação foi apresentado por Fernandes et al. (2012).

Os participantes demonstraram interesse em aplicar os conceitos apresentados na palestra em seu cotidiano. De maneira geral, pode-se evidenciar que o conhecimento repassado foi absorvido de maneira integral e satisfatória.

Evidenciou-se, ainda, que durante as palestras o público-alvo não apresentava conhecimentos básicos sobre medição e registro de dados pluviométricos. Entretanto, foi possível observar que eles compreendiam a importância da coleta das informações de chuva e do grau de dependência da produtividade do cafeeiro em relação ao regime pluviométrico da região. 

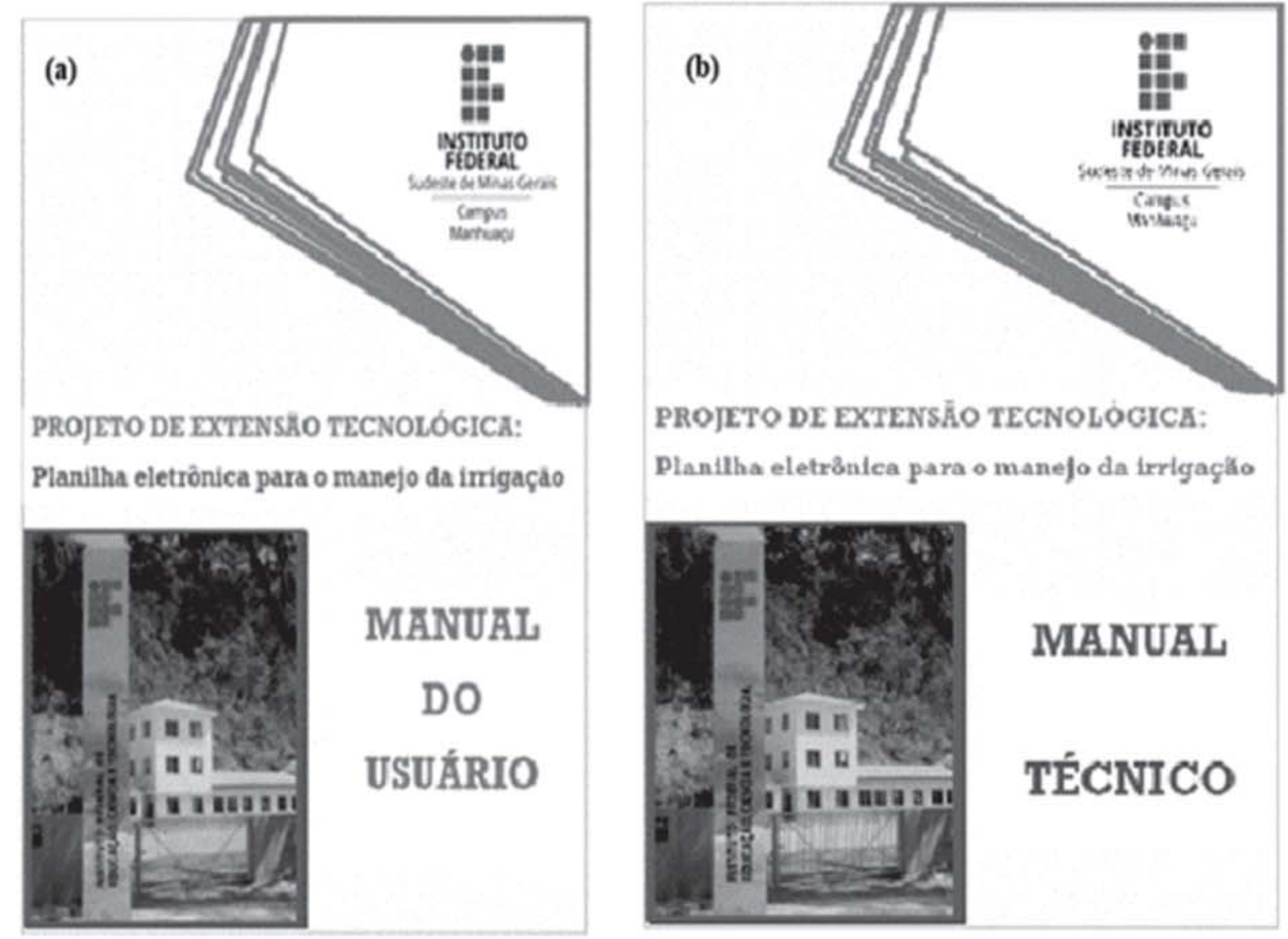

Planillha eletrônica para o manejo da irrigaçắo

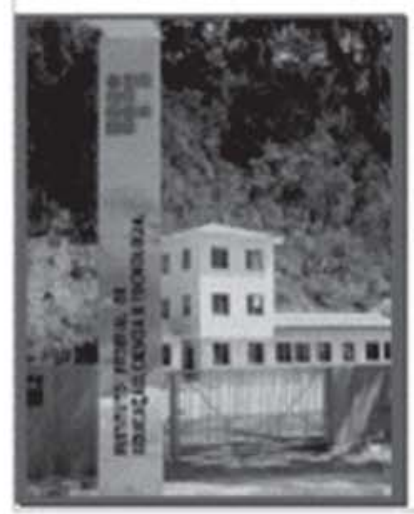

\section{MANUAL}

\section{TÉCNICO}

(c)

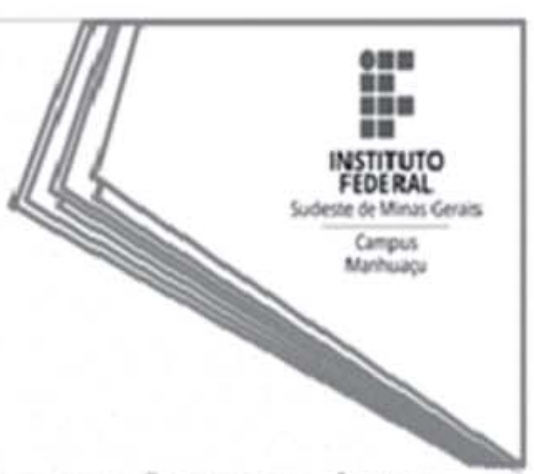

PROJETO DE EXTENSÃO TECNOLÓGICK:

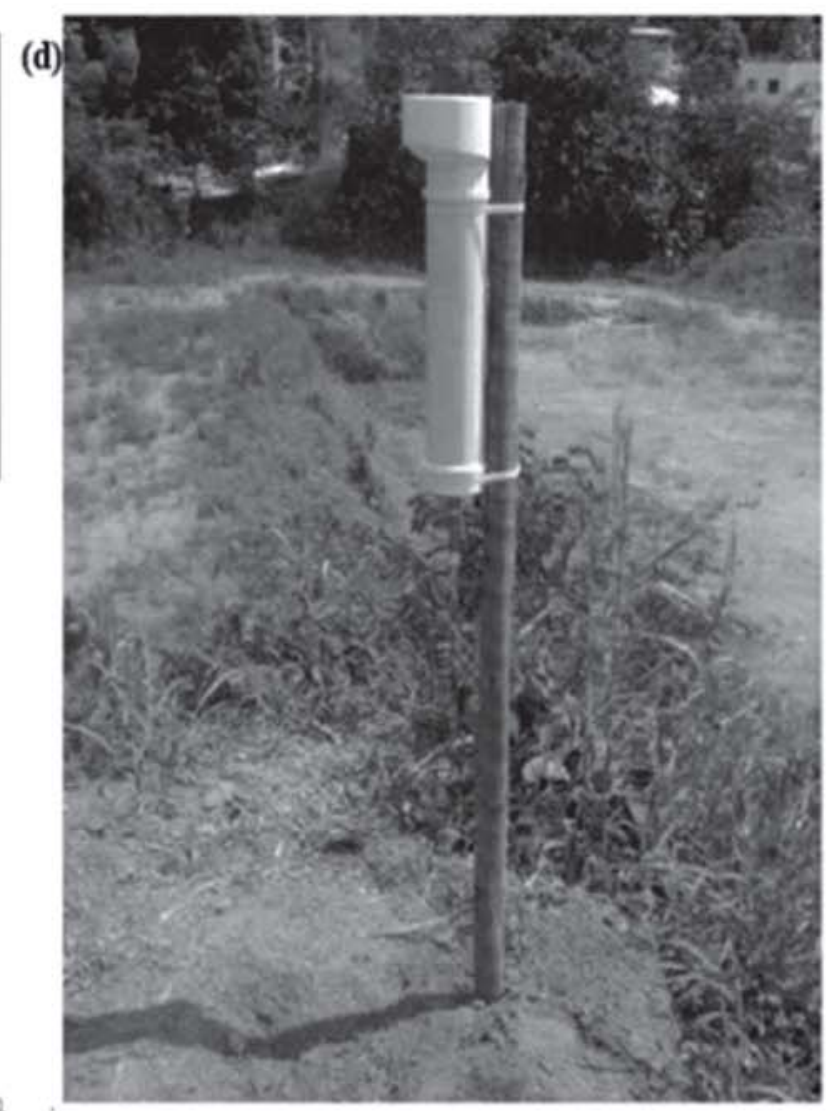

Figura 4 - (a) Capa do manual do usuário; (b) Capa do manual técnico; (c) Capa do manual de construção de um pluviômetro de baixo custo; (d) Foto do pluviômetro construído durante as atividades do projeto.

Fonte: Dados da pesquisa. 

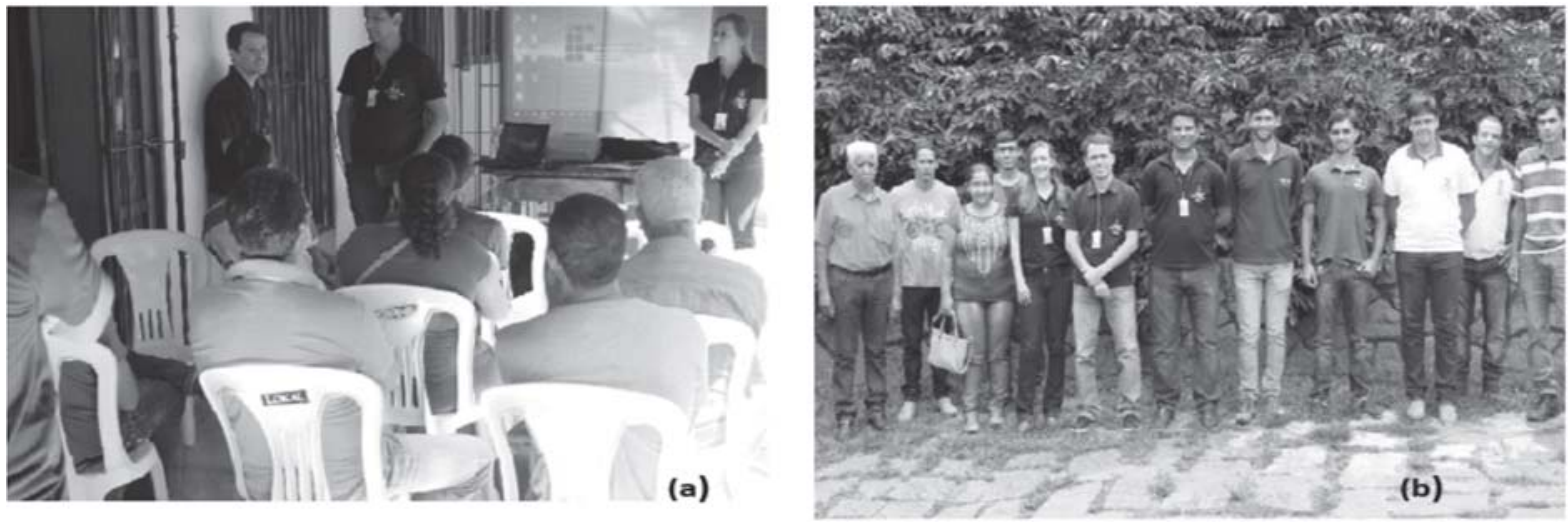

Figura 5 - (a) Palestra de disseminação de conhecimentos sobre o manejo da irrigação na cultura do cafeeiro; (b) representantes do público alvo e equipe de extensão.

Fonte: Dados da pesquisa.

$\mathrm{Na}$ tentativa de disseminar de maneira adequada os conhecimentos inerentes a prática de coleta de dados de chuva, a equipe de extensão elaborou um Manual de Construção de um Pluviômetro de Baixo Custo. Esse documento apresenta, assim como o Manual do Usuário, um passo a passo para construção do equipamento. Neste cenário, o manual foi distribuído aos representantes do públicoalvo para difundir as técnicas de construção e coleta de informações. Na Figura 4c e 4d estão apresentadas a capa do manual e o pluviômetro construído durante as atividades do projeto.

A coleta de dados de chuva é de extrema importância para o manejo da irrigação. Essa variável climática representa a principal forma de entrada de água no sistema; portanto, o conhecimento da quantidade de chuva ocorrida em determinado período, permite ao irrigante descontar a quantidade de chuva da lâmina de irrigação recomendada e até mesmo decidir sobre o melhor momento para dispender esforços para a irrigação (BERNARDO, 2008).

Finalizadas as atividades do projeto, a equipe de extensão se reuniu e decidiu divulgar por meio do site do Instituto Federal do Sudeste de Minas Gerais - Campus Manhuaçu, a ferramenta desenvolvida no projeto e seus manuais. Essa ação permitirá a divulgação contínua do conhecimento gerado no projeto, disseminando cada vez mais a importância do uso racional da água na cafeicultura irrigada, contribuindo, assim, para a melhor gestão da água nas propriedades cafeeiras e promovendo uma crescente proteção dos recursos hídricos locais.

\section{Conclusões}

A busca por fomentar o debate democrático com relação ao uso racional da água na cafeicultura irrigada, bem como disseminar conhecimentos sobre a importância do manejo da irrigação na cultura do cafeeiro, possibilitou dialogar com a sociedade cafeeira, principalmente, com setores da cafeicultura familiar sobre as dificuldades cotidianas da utilização de sistemas de irrigação, apresentando soluções para as dificuldades encontradas.

Foi possível diagnosticar um determinado padrão de mudança na relação entre o homem do campo e o acesso às ferramentas computacionais e, a partir daí, elaborar e difundir uma ferramenta específica para o manejo da irrigação, apresentado uma solução simples, gratuita e de fácil acesso aos pequenos irrigantes.

As palestras, as reuniões e os debates, permitiu que apresentássemos a importância do correto planejamento do uso da água, demonstrar que é possível aumentar a produtividade e a qualidade do café produzido na região de Manhuaçu-MG, aplicando a lâmina de água correta para suprir a demanda hídrica do cafeeiro e, consequentemente, minimizando os desperdícios. Importante destacar que os debates foram extremamente relevantes para elevar o conhecimento regional sobre os conceitos básicos da irrigação na cultura do café, além de nos fazer perceber que o conhecimento referente a conceitos de física do solo ainda pode ser considerado um grande entrave ao correto manejo de sistema de irrigação na região.

Por fim, ressalta-se que com o intuito de atingir cada vez mais irrigantes, todos os produtos gerados nesse projeto estão disponibilizados no site institucional do Instituto Federal do Sudeste de Minas Gerais, Campus Manhuaçu. 


\section{Fontes de financiamento}

O Projeto "Planilha eletrônica para manejo da irrigação na cultura do cafeeiro" recebeu apoio financeiro do Instituto Federal do Sudeste de Minas Gerais, por meio da Pró-Reitoria de Extensão, através do edital de Extensão Tecnológica do Programa de Apoio as Atividades de Extensão (PIAEX).

\section{Agradecimentos}

Aos egressos do Curso técnico em Cafeicultura e do Curso técnico em Informática: Keila Helena, Leonardo Vieria Frossard, Murilo Garcez Frossard, Otávio de Oliveira Garcia, Vanessa da Costa Aguiar, Natália Nayara Rosa e Victor Novais pelo empenho durante as atividades do projeto. À Hidrat Irrigação Planejada LTDA pela contribuição técnica durante as atividades e pela disponibilidade de espaço e organização da palestra de disseminação de conhecimentos.

\section{Referências}

BERNANDO, Salassier; SOARES, Antônio Alves; MANTOVAI, Everardo Chartuni. Manual de Irrigação. Viçosa: Editora UFV, 2008. 625p.

CONAB. COMPANHIA NACIONAL DE ABASTECIMENTO. Acompanhamento da Safra Brasileira: Café. Brasília: Conab, 2018. 70 p.

FERNANDES, André Luis Teixeira et al. A Moderna cafeicultura dos cerrados brasileiros. Pesquisa Agropecuária Tropical, Goiânia, v. 42, p.231-240, abr/jun. 2012.

FERNANDES, André Luis Teixeira et al. Viabilidade técnica e econômica da irrigação localizada no cafeeiro, nas condições climáticas do planalto de Araxá, MG. Coffee Science, Lavras, v. 11, n. 3, p.346-356, jul./set. 2016.

FERNANDES, André Luís Teixeira; SANTINATO, Roberto; FERNANDES, Durval Rocha. Irrigação na cultura do café. Belo Horizonte: O Lutador, 2008. 476 p.

LIMA, Luiz Antônio; CUSTÓDIO, Anselmo Augusto de Paiva; GOMES, Natalino Martins. Produtividade e rendimento do cafeeiro nas cinco primeiras safras irrigado por pivô central em Lavras, MG. Ciência e Agrotecnologia, [s.l.], v. 32, n. 6, p.1832-1842, dez. 2008. FapUNIFESP (SciELO). http:/ /dx.doi.org/10.1590/s1413-70542008000600023.

MANTOVANI, Everardo Chartuni et al. Irrigação como fator de qualidade do café. In: ZAMBOLIM, Laércio. Boas práticas agrícolas na produção de café. Viçosa: UFV, 2006. p. 117-165.

SILVA, Adriana L. da; FARIA, Manoel A. de; REIS, Ricardo P. Viabilidade técnico-econômica do uso do sistema de irrigação por gotejamento na cultura do cafeeiro. Revista Brasileira de Engenharia Agrícola e Ambiental, [s.1.], v. 7, n. 1, p.37-44, abr. 2003. FapUNIFESP (SciELO). http://dx.doi.org/ $10.1590 / \mathrm{s} 1415-43662003000100007$.

SOARES, Adilson Rodrigues et al. Irrigação e fisiologia da floração em cafeeiros adultos na região da zona da mata de Minas Gerais. Acta Scientiarum. Agronomy, [s.1.], v. 27, n. 1, p.117-125, 11 abr. 2005. Universidade Estadual de Maringa. http://dx.doi.org/10.4025/actasciagron.v27i1.2128.

VICENTE, Marcelo Rossi et al. EFEITO DE DIFERENTES LÂMINAS DE IRRIGAÇÃO NAS VARIÁVEIS DE DESENVOLVIMENTO E PRODUÇÃO DO CAFEEIRO IRRIGADO POR PIVÔ CENTRAL. Irriga, [s.1.], v. 20, n. 3, p.528-543, 28 out. 2015. Brazilian Journal of Irrigation and Drainage - IRRIGA. http://dx.doi.org/10.15809/irriga.2015v20n3p528.

Data de submissão: 12/2/2019. Data de aceite: 3/5/2019. 